Paakat: Revista de Tecnología y Sociedad

e-ISSN: 2007-3607

Universidad de Guadalajara

Sistema de Universidad Virtual

México

suv.paakat@redudg.udg.mx

Año 10, número 18, marzo-agosto 2020

\title{
Inteligência artificial e o problema da intencionalidade
}

\author{
Artificial intelligence and the problem of intentionality
}

\section{Inteligencia artificial y el problema de la intencionalidad}

\author{
Alexandre Quaresma* \\ http://lattes.cnpq.br/6089915050124806 \\ Pontificia Universidad Católica de São Paulo, Brasil
}

[Recibido 26/11/2018. Aceptado para su publicación 3/10/2019]

DOI: http://dx.doi.org/10.32870/Pk.a10n18.403

\section{Resumo}

Nesse artigo, investigaremos como acontece a intencionalidade no mundo biológico, quais as condições necessárias para sua manifestação, como os animais superiores lidam com ela objetivamente em seus acoplamentos estruturais com o meio, correlacionando-a (intencionalidade) enquanto fenômeno genuinamente biológico, com a dificuldade de instanciar inteligências conscientes e intencionais em sistemas cibernético-informacionais complexos e artificiais. Mais especificamente, referimo-nos a tentar fazê-lo -como defende o cognitivismo ortodoxo- em computadores, androides e robôs, por meio de arranjos de IA (Inteligências Artificiais). Vale destacar que esse problema da intencionalidade se vê intimamente relacionado a problemas que já discutimos em trabalhos anteriores (Inteligências artificiais e o problema do consciência; Inteligências artificiais e os limites da computação), no sentido de que, apenas um sistema ou ser biológico vivo é capaz de possuir essas três faculdades-propriedades importantíssimas ao mesmo tempo; a saber: consciência, intencionalidade e emoção.

\section{Palavras-chave}

Inteligência artificial; intencionalidade; limites da computação; crítica da tecnología. 


\begin{abstract}
In this article, we will investigate how intentionality in the biological world happens, what conditions are necessary for its manifestation, how the upper animals objectively deal with it in their structural couplings with the environment, correlating it (intentionality), as a genuinely biological phenomenon, with the difficulty of instantiating conscious and intentional intelligences in complex and artificial cybernetic-informational systems. More specifically, we refer to trying to do so -as it defends orthodox cognitivism- in computers, androids and robots, through AI arrangements (artificial intelligences). It is noteworthy that this problem of intentionality is closely related to problems we have already discussed in previous works (artificial intelligences and the problem of consciousness; Artificial intelligences and the Limits of computation), in the sense that, only a system or being a living biological is able to possess these three faculties-important properties at the same time; namely: consciousness, intentionality and emotion.
\end{abstract}

\title{
Keywords
}

Artificial intelligence; Intentionality; Limits of computing; Criticism of technology.

\section{Resumen}

En este artículo, investigaremos cómo ocurre la intencionalidad en el mundo biológico, qué condiciones son necesarias para su manifestación, cómo los animales superiores la tratan objetivamente en sus acoplamientos estructurales con el medio ambiente, correlacionándola (intencionalidad) como fenómeno genuinamente biológico, con la dificultad de crear inteligencias conscientes e intencionales en sistemas de información cibernética complejos y artificiales. Más concretamente, nos referimos a tratar de hacerlo -como lo defiende el cognitivismo ortodoxo- en ordenadores, androides y robots, a través de arreglos de IA (inteligencias artificiales). Cabe destacar que este problema de intencionalidad está estrechamente relacionado con los problemas que ya hemos discutido en anteriores obras (Inteligencias artificiales y el problema de la conciencia; Inteligencias artificiales y los límites de la computación), en el sentido de que, sólo un sistema o ser biológico viviente es capaz de poseer estas tres facultades-propiedades importantes al mismo tiempo; a saber: conciencia, intencionalidad y emoción.

\section{Palabras clave}

Inteligencia artificial; intencionalidad; límites de la informática; crítica de la tecnología.

\section{Intencionalidade e sentido}

Muitas das importantes funções evolutivas da consciência são evidentemente intencionais: os animais, por exemplo,

têm sensações conscientes de fome e sede, ocupam-se com discriminações perceptivas conscientes, envolvem-se em ações intencionais conscientes e reconhecem conscientemente amigos e inimigos. Todos esses fenômenos são intencionais e conscientes, e também essenciais para a sobrevivência biológica

John Searle (2010, p. 65)

O problema da intencionalidade passa -no que se refere às simulações em inteligências artificiais- pelos mesmos tipos de problemas que passa o problema da consciência. Objetivamente, referimo-nos às tentativas de instanciar consciência intencional e inteligente em sistemas cibernético-informacionais, ou, mais simplesmente, em computadores, androides e robôs. A intencionalidade enquanto faculdade-propriedade é um estado não só cognitivo -sustentamos-, mas também necessariamente biológico, que requer 
igualmente um agente, um corpo, um protagonista, um sujeito, um cérebro, vínculos com a história bioevolutiva pregressa, com as cadeias tróficas, e assim por diante, exatamente como no caso do problema da consciência.

Passa, também, pela questão do sentido, o que vale dizer, o sistema artificial tem de ser capaz de internalizar o valor do que seja o sentido, fazer sentido, ter sentido, além de atribuir e avaliar constantemente o valor das coisas do mundo, da realidade, desde enunciados e frases, até -no extremo- ser capaz de sopesar o sentido de sua própria razão de existir. Existir, em muitos aspectos, significa buscar e alcançar a finalidade última do próprio conceito de fazer sentido para si mesmo, em relação ao mundo e também às outras pessoas e seres. Enfim, o sentido de se ter um sentido, e o sentido de buscá-lo para também conceder sentido a sua própria singularidade diante do objeto dinâmico que é o tempo e a realidade, é o sentido último da própria busca pelo sentido, arriscamos nós.

A intencionalidade só existe se houver um agente consciente que possua a referida intenção, uma subjetividade que busque ou faça o sentido ter valor objetivo em si mesmo, que avalie e modifique esse sentido, adaptando-o e significando-o constantemente. De modo que, sem agente, sem consciência, sem subjetividade, sem intenção -é claro e óbvio-, não poderá haver também intencionalidade.

Mesmo o conceito de intencionalidade em si só é relevante e acessível cognitivamente se houver um sujeito intencional que conceitue essa importante propriedade-faculdade biológica chamada intencionalidade, e que tenha a intenção de fazê-lo. Que a faça ter sentido. Lembrando que sua falta ou ausência pode determinar também, no extremo oposto, o que é vivo e o que não é. Uma pedra não possui intencionalidade, um ser vivo sim.

E, abordar a questão da intencionalidade, leva-nos ao fato irremovível de que não podemos compreender a intencionalidade fora de um âmbito de subjetividade intencional absolutamente biológica, que envolve uma série de outras questões também de cunho biológico. Algo como um silogismo categórico clássico da lógica aristotélica, expresso numa noção bem formulada: se há intencionalidade, há necessariamente sujeito, e se há sujeito, logo há, necessariamente, um organismo biológico.

A notação lógica desse raciocínio formal é a seguinte: Todo organismo biológico é um sujeito. Todo sujeito é intencional. Logo, todo organismo biológico é intencional. Em linguagem simbólica grafar-se-ia assim: Todo $O$ é $S$, todo S é I, logo, todo O é I. John Searle (2002, p. 36) é enfático:

Em minha opinião, não é possível apresentar uma análise lógica da Intencionalidade do mental em termos de noções mais simples, uma vez que a 
Intencionalidade é, por assim dizer, uma propriedade fundamental da mente e não uma característica logicamente complexa construída a partir da combinação de elementos mais simples. Não existe uma posição neutra a partir da qual possamos investigar as relações entre estados Intencionais e o mundo para depois descrevê-las em termos não-intencionais. Qualquer explicação da Intencionalidade, portanto, tem lugar nos limites dos conceitos intencionais.

Observemos que, como sugere John Searle (2010, pp. 64-65), 1) "os estados conscientes normalmente têm 'intencionalidade', aquela propriedade de muitos de nossos estados mentais de 'se dirigir a' ou de 'versar sobre' objetos e estados de coisas do mundo". E que 2) possui intencionalidade "todo fenômeno mental que tenha conteúdo referencial. De acordo com esse uso, todas as crenças, esperanças, intenções, medos, desejos e percepções são intencionais". Além disso, como nos explica também John Searle (2006, p. 189),

minhas experiências conscientes, ao contrário dos objetos das experiências, são sempre em perspectiva. São sempre a partir de um ponto de vista. Mas os objetos em si não têm ponto de vista. Perspectiva e ponto de vista são mais óbvios para a visão, mas certamente são também características de nossas outras experiências sensoriais. Se toco a mesa, experimento-a apenas sob determinados aspectos e a partir de uma certa posição espacial. Se ouço um som, ouço-o unicamente de uma certa direção e ouço determinados aspectos dele. E assim por diante.

E aqui chegamos a um ponto interessantíssimo que merece ser apreciado com atenção. "Se tento observar a consciência de outro", informa-nos John Searle (2006, p. 143), "o que observo não é sua subjetividade, mas simplesmente seu comportamento consciente". "O mundo mesmo não tem ponto de vista", continua Searle (2006, p. 140), "mas meu acesso ao mundo através de meus estados conscientes se dá sempre em perspectiva, sempre a partir de meu ponto de vista". Enfim, o mundo só existe para nós no sentido da nossa perspectiva em relação ao mundo, enquanto que o mundo, por sua vez, não possui ponto de vista nem perspectiva alguma.

\section{Intencionalidade corpórea}

Tratamos -atentemos- de corpos biológicos que possuem cérebros, que exibem inteligência e consciência em níveis elevados, e que -por finalidade- produzem subjetividade e intencionalidade, pois precisam delas para sobreviver, ou seja, para poder performar no mundo e no ambiente com um mínimo de eficiência e propriedade, há que se ter intencionalidade. Não existem dicotomias ou paradoxos aqui. 
Sem maiores embargos, inteligência, consciência, subjetividade e intencionalidade -sustentamos-, são todas adaptações bioevolutivas direcionadas para os processos decisivos e fundamentais da sobrevivência de cada ser individual. Está na literatura. E todo animal inteligente e consciente é necessariamente também um agente intencional, não há como fugir disso.

Um pequeno primata que se lança de um galho a outro agilmente em busca de uma fruta, uma lebre que foge de um gavião, um gato que se esquiva agilmente de um cão mal-humorado, um rato que foge de um gato; todos esses são comportamentos necessariamente intencionais, inteligentes, conscientes, que provocam emoções e sentimentos. Para que tais fenômenos possam ocorrer objetivamente, há que se ter necessária e concomitantemente o sujeito inteligente, a consciência de si em relação ao momento, ao lugar, há que se ter uma intenção consciente de agir, e a ação coordenada de um corpo saudável que gerará os comportamentos mais apropriados e eficientes em relação ao meio ambiente dinâmico que o contêm.

Enfim, há que se ter um organismo completo e articulado dialogando com o entorno, com o clima, com seus iguais, concorrentes, predadores e assim por diante. A locomoção, alimentação, o acasalamento, a luta; todos esses são comportamentos intencionais e biológicos. Difícil mesmo é refutar. Além disso, como nos informa John Searle (2010, p. 65),

\begin{abstract}
muitas das importantes funções evolutivas da consciência são evidentemente intencionais: os animais, por exemplo, têm sensações conscientes de fome e sede, ocupam-se com discriminações perceptivas conscientes, envolvem-se em ações intencionais conscientes e reconhecem conscientemente amigos e inimigos. Todos esses fenômenos são intencionais e conscientes, e também essenciais para a sobrevivência biológica.
\end{abstract}

E, aqui, leiamos "biológica" como a lógica organizacional da vida. E a estruturação dessa vida biológica inteligente se dá por meio de organismos que possuem cérebros, e, como escreve John Searle (2010, p. 69), "a relação dos mecanismos cerebrais com a consciência é causal". Enfim, são os processos e dinâmicas de nível inferior, nomeadamente células, tecidos, neurônios, sinapses e atividade neuronal, estimuladores, supressores, ativadores, inibidores, que produzem os fenômenos da consciência, subjetividade e intencionalidade.

Manifestações mais bioquímicas e físicas do que transcendentais e místicas, mais objetivas e causais, do que misteriosamente desconhecidas e indeterminadas. O mesmo autor (2010, p. 69) também sustenta que, "assim como a água pode estar em estado líquido ou sólido, sem que a liquidez e a solidez constituam substâncias separadas, também a consciência é um estado no qual o cérebro se encontra, sem que a consciência seja uma substância separada". O cérebro produz consciência, e "a consciência" acrescenta Searle 
(2010, p. 72), "é um fenômeno biológico como qualquer outro e que consiste nos estados internos, qualitativos e subjetivos de perceber, sentir e pensar". Para nós, algo que parece bastante claro e razoável.

Todavia -não nos enganemos- há problemas aparentemente insolúveis que insistem em nos assolar, como consta em Massimo Negrotti (2012, p. 405):

Por um lado, podemos ver a mente simplesmente como o desempenho do cérebro, mas por outro, devemos admitir que cada chamada atividade mental do cérebro não é necessariamente rastreável a alguma estrutura cerebral isomórfica, enquanto que, dentro de certos limites, podemos localizar a estrutura cerebral envolvida, digamos, a contração de um determinado músculo.

Negrotti (2012, p. 405) acrescenta em tom de alerta:

Só porque um modelo da mente não pode deixar de lado o cérebro como o motor da nossa consciência, raciocínio, tomada de decisão, e assim por diante, a tentativa de reproduzir o comportamento mental artificialmente está, se concebida como uma empresa que vê a mente como um sistema autônomo, sem dúvida destinada a falhar. Ou melhor, a reprodução de um processo mental em um programa de computador, por exemplo, através de cálculos ou raciocínio, pode ser bem-sucedido não porque ele captura a forma complexa de raciocínio dos seres humanos, mas porque reproduz os resultados finais do funcionamento do cérebro.

"Assim, na medida em que o problema da reprodutibilidade do cérebro está em causa", informa-nos Negrotti (2012, p. 407), "grande parte da dificuldade no projeto depende do nosso conhecimento bastante pobre de seus possíveis níveis de observação". Além disso, acrescenta Negrotti $(2012$, p. 407), "seria ainda mais difícil decidir qual nível deve ser considerado o mais indispensável para gerar o desempenho essencial do cérebro - ou seja, o que chamamos de estados mentais e processos".

Mas, de toda maneira e também à revelia de nossa ignorância sobre o funcionamento inconsútil do cérebro, o ato de pensar em algo, por exemplo, necessariamente requer intenção. Se -por exemplo- penso em refletir sobre $o$ problema da intencionalidade, como de fato estou fazendo agora, e penso igualmente em escrever, e de fato escrevo sobre os resultados de minhas reflexões, é a minha intenção subjetiva que está agindo junto com a minha própria percepção de mundo, de mim mesmo e, especialmente, de minha consciência intencional direcionada à produção de textos acadêmicos para a construção do conhecimento.

Desejo explorar tal problema, e me agrada imaginar que meus textos podem ajudar outras pessoas a compreender melhor $\mathrm{O}$ assunto. $\mathrm{E}$ a 
intencionalidade, seja em maior ou menor grau, está absolutamente presente nesse tipo de comportamento, e todas as demais formas de vida também exercem de alguma maneira a sua intencionalidade no dia a dia, assim como nós. A ação de uma planta, embrenhada em meio à profusão de muitos outros vegetais, que realiza um fototropismo sinuoso -inclinando-se na direção da luz-, também poderia, num certo grau de complexidade bem menor, ser considerada uma espécie de ação intencional.

Ela identifica sensivelmente a direção da fonte de luz, e, como precisa dela, inclina-se fisicamente em sua direção, em busca de uma posição que lhe permita recebê-la em maior quantidade e qualidade. É claro que alguns dirão o contrário, mas aqui -enquanto não houver provas- trata-se de matéria de crença e opinião. Mas, retornando aos seres complexos com cérebros também complexos e explícita intencionalidade, é possível entender facilmente que, como escreve John Searle (2010, pp. 124-125),

os fenômenos mentais intencionais fazem parte da nossa história de vida natural e biológica. Sentir sede e ter experiências visuais, desejos, medos e expectativas faz parte da história de vida biológica de uma pessoa tanto quanto respirar, digerir e dormir. Os fenômenos intencionais, como os outros fenômenos biológicos, são características reais intrínsecas de certos organismos biológicos, do mesmo modo que a mitose, a meiose e a secreção da bile são características reais de certos organismos biológicos.

Quanto a isso, ou seja, a questão da intencionalidade em animais complexos, John Searle (2010, p. 98) não deixa dúvida, e nós, por nosso turno, também não temos como discordar:

Humanos, cachorros e chimpanzés recebem estímulos perceptivos por meio dos receptores sensíveis visuais, táteis, auditivos, olfativos e outros; todos eles enviam os sinais produzidos por esses estímulos para o cérebro, onde são processados; e, por fim, os processos cerebrais resultantes provocam respostas motoras na forma de ações intencionais como: socializar com outros animais coespecíficos, comer, brincar, lutar, reproduzir, educar os filhotes e tentar permanecer vivo. Dada a continuidade neurobiológica, parece fora de questão supor que somente os humanos tenham intencionalidade e pensamento.

Quem assim pensa, ou seja, que apenas nós possuímos tais faculdades, certamente está contaminado com um antropocentrismo tão desmedido e uma insensibilidade tão exacerbada, que seu juízo e razão já foram contaminados e comprometidos, de modo que seria difícil querer com eles tentar argumentar.

Como já mencionado anteriormente em artigo de nossa lavra (Inteligências artificiais e o problema da consciência, Alexandre Quaresma, 2018), existem algumas visões contraditórias e realmente frágeis acerca da 
intencionalidade consciente, que negam seus aspectos causais mais basilares da biologia, bem como sua própria manifestação fenomênica, e um desses pesquisadores de razoável notoriedade que enxerga as manifestações biológicas de forma no mínimo estranha é Daniel Dennett. John Searle (2010, p. 127) que é um crítico ferrenho desse último, e, em referência não nominada a ele, escreve o seguinte:

\begin{abstract}
Afirma-se às vezes que a mente com seus estados intencionais é algo abstrato, como um programa de computador ou um fluxograma; ou que os estados mentais não têm natureza mental intrínseca, porque podem ser inteiramente definidos em relação as suas causas e efeitos; ou que não há nenhum estado mental intrínseco, mas que falar em estados mentais é somente um jeito de lidar com o meio que nos cerca; e chega-se mesmo a dizer que definitivamente não se deveria pensar que os termos mentais representam coisas reais do mundo.
\end{abstract}

"Mas, parafraseando Darwin" acrescenta Searle (2010, p. 127), "o fato de o cérebro causar fenômenos mentais não é mais misterioso que o fato de os corpos terem gravidade". Nessa mesma linha de raciocínio inconsistente e de fato frágil de Dennett, não condizente com as observações empíricas passíveis de serem efetuadas no mundo natural, encontram-se aqueles que chegam a duvidar da nossa própria percepção sensória do mundo, ou seja, aqueles que duvidam dos próprios sentidos: os céticos radicais. Algo como o "Gênio Maligno" de René Descartes, figura mítica muitíssimo conhecida na filosofia, alvo (inclusive) de um relativo deboche. Em resposta a eles, John Austin (2004, pp. 7-8) chega a ser irônico e cita John Locke:

Não tenho a menor dúvida de estar efetivamente percebendo objetos familiares, cadeiras e mesas, quadros, livros e flores que mobíliam a minha sala; estou, portanto, convencido de que existem. Reconheço, de fato, que às vezes os sentidos enganam, mas isso não me leva a suspeitar de que as minhas percepções sensórias não sejam, em geral, dignas de confiança, ou mesmo que possam estar me enganando neste exato momento. E esta não é, acredito, uma atitude excepcional. Creio que, na prática, a maior parte das pessoas concorda com John Locke em que 'a certeza da existência das coisas in rerum natura [ao natural], quando temos o testemunho dos sentidos para nos apoiarmos nela, não constitui apenas o mais alto grau que nossa constituição física pode alcançar, mas é, também, proporcional às necessidades impostas por nossa condição'.

Assim sendo, argumentamos nós, se despimos a faculdade-propriedade da intencionalidade de seus laços inquebrantáveis com o contexto biológico em que ela surge e acontece, ou seja, se a separamos da inteligência, da consciência, da fisiologia do cérebro, da corporalidade física, da complexidade dos organismos biológicos vivos que a manifestam, ao final não teremos absolutamente nada que possa amparar o fato de a consciência intencional subjetiva acontecer bem diante de nós, e até em nós mesmos. 
Daí surge toda má sorte de crenças e mitos, dicotomias e paradoxos, que por si e a priori, são na verdade falsos problemas, ou problemas mal formulados, e, por isso mesmo, muitas vezes, de saída, insolúveis. Assim, poder compreender que fazemos parte das cadeias tróficas como os demais seres vivos, e que apenas os graus de inteligência e consciência é que variam de acordo com a necessidade adaptativa entre nós, facilita a compreensão da própria história bioevolutiva que se deu no planeta Terra. E é justamente por isso que Francisco Varela, Evan Thompson e Eleonor Rosch (1991, p. 256) sustentam que, "grande parte daquilo que um organismo aparenta e a que 'diz respeito' é completamente subdeterminado pelos constrangimentos de sobrevivência e reprodução".

Mas, se seguimos o conselho de John Searle (2002, p. 32), e deixamos de lado as preocupações sobre "como o mundo deveria funcionar" e, em vez disso, tentamos "compreender como ele de fato realmente funciona", deparar-nosemos com desafios enormes no que tange à consciência intencional, é verdade, mas pelo menos partiremos com nossas reflexões de conhecimentos e recorrências fáticas que possuem alto grau de verdade, pois são manifestos e observáveis, seja pela primeira, seja pela terceira pessoa. Eis aqui, por uma questão de lealdade, as palavras do próprio John Searle: "O desafio consiste em deixar de lado nossa preocupação sobre como o mundo deveria funcionar e, em vez disso, tentar compreender como ele realmente funciona". Searle (2010, p. 132) escreve:

\footnotetext{
Creio que, se pudéssemos esquecer a tradição [e aqui o autor se refere principalmente à dualidade cartesiana mente-cérebro], a questão sobre o lugar desses estados [mentais] na natureza teria uma resposta óbvia. Eles são estados físicos de certos sistemas bioquímicos, a saber, os cérebros. Os estados mentais, com todas as suas características gloriosas ou enfadonhas -consciência, intencionalidade, subjetividade, alegria, angústia etcetera- são exatamente como sempre soubemos que são.
}

Enfim, eles são fenômenos biológicos. Como nos ensina Michael Wheeler (2005, p. 14), "'as aparências enganam' é um ditado que ensinamos aos nossos filhos, em uma tentativa de impedir que essas mentes jovens e crédulas tomem tudo ao seu valor nominal". "Mas é um aviso que é tão útil para o aluno da teoria cognitiva como é para o aluno da vida", e "aqui está o porquê", escreve Wheeler (2005, p. 14): "Apesar das aparências, a maioria de pesquisa na ciência cognitiva, esse bastião do pensamento contemporâneo, é irreconhecivelmente cartesiano no caráter", ou seja, é baseada numa lógica que remonta ao século XVII.

Enfim, algo que pretende ignorar quase quatrocentos anos de história e ciência natural sobre os organismos vivos. Quanto a isso, Wheeler (2005, p. 14) é instrutivo, e sustenta que "a maioria dos trabalhos dos cientistas cognitivos [...] está fundado nos compromissos, conceitos e princípios explicativos que 
constituem os pressupostos profundos do campo". "No entanto, apesar da natureza oculta desta presença cartesiana", informa-nos Wheeler (2005, p. 14),

sua influência foi identificada e descrita por (entre outros) Bickhard e Terveen (1996), Dennett (1991), Dreyfus (1991), Dreyfus e Dreyfus (1988), Fodor (1983), Harvey (1992), Haugeland (1995/1998), Lemmen (1998), Shanon (1993), Van Gelder (1992), Varela, Thompson, e Rosch (1991), e Wheeler (1995, 1996a, 1996b, 1997). [...] Para qualquer pessoa interessada nos fundamentos filosóficos da ciência cognitiva, este seria um bom lugar para começar.

Todos esses autores supracitados identificaram uma similitude nas diversas teorias cognitivas, como nos explica Wheeler (2005, p. 15), uma espécie de forma ou "conceito integrado e explicativo de quadro para compreender cientificamente a mente, a cognição e a inteligência". Michael Wheeler (2005, p. 15) não tem dúvidas:

Este quadro, que eu chamo de psicologia cartesiana, é definido por [...] princípios explicativos que capturam as maneiras pelas quais vários fatores cruciais estão localizados e jogados fora no próprio relato da mente de Descartes. Esses fatores são o sujeito - dicotomia do objeto, representações, razão generalícia, o caráter da percepção, a estrutura organizacional da ação inteligente perceptualmente guiada, o corpo, o ambiente e a temporalidade.

Todavia, como escreve Wheeler (2005, p. 284),

Parece que estamos no meio de uma virada anticartesiana na ciência cognitiva. As primeiras sugestões desta transformação nascente no campo devem ser encontradas em alguns exemplos-chave de pesquisa de sistemas dinâmicos [...]. No entanto, estes são pontos de pressão dispersos na hegemonia cartesiana. Ir além do cartesianismo na ciência cognitiva requer uma reconstrução mais fundamental nos fundamentos filosóficos da disciplina.

\section{Um breve estudo de caso}

Para ilustrar essa questão da intencionalidade, e para avançarmos um pouco mais com nossas argumentações através de exemplos instrutivos, tomemos a seguir um fato real como objeto de análise e estudo de caso. Eis que enquanto escrevíamos esse artigo, que integra a nossa dissertação de mestrado para o programa pluridisciplinar do TIDD (Tecnologias da Inteligência e Design Digital), da PUC/SP, em nossa casa ao lado da Mata Atlântica brasileira no Rio de Janeiro, acabamos estreitando os nossos laços de amizade com um grupo de micos silvestres que passou a nos visitar nesse memorável inverno de 2018 pelo menos duas vezes por dia. 
Nós (eu e minha esposa) eventualmente já os alimentavámos, mas fato é que recentemente estabeleceu-se um padrão de comportamento intencional consciente e recíproco muitíssimo interessante, que poderia ser descrito resumidamente assim: nós sentimos prazer em alimentar os seres silvestres da Mata Atlântica, e de fato o fazemos intencionalmente sempre que possível. Os pequenos macacos desse bioma são seres nômades que adoram banana e, quando se locomovem em bandos se comunicam por meio de vocalizações, e, quando se aproximam das árvores perto da casa, é possível identificar seus silvos, guinchos e estalidos característicos, por meio das quais se expressam e se comunicam entre si, que, por sua vez, me informam de imediato que eles estão nas imediações da casa.

Eu, por minha vez, interrompo momentaneamente a pesquisa e a redação acadêmica, para apanhar na cozinha uma ou duas bananas e ir servir aos macaquinhos, fazendo também - por minha parte- vocalizações humanas em que tento expressar a minha amistosidade e afeto em relação a eles, que por sua vez, é também intencional. Ao ouvirem a minha voz, e também devido ao hábito que se estabeleceu depois da décima ou vigésima vez que isso aconteceu, mesmo ainda distantes, em árvores das redondezas e da vizinhança, era possível observar esses pequenos animais se lançando impetuosamente de uma árvore a outra, às vezes a dois ou três metros de distância entre galhos, para poderem chegar mais rápido ao seu objetivo intencional, ou seja, vir até mim para apanhar seu alimento predileto: apetitosas bananas maduras.

É o que John Searle chama de relação entre "estados intencionais" e "condições de satisfação". Em suma, sustenta John Searle (2017, p. 82-83),

resumindo a discussão da intencionalidade, há três características que precisamos de ter em conta na nossa análise do comportamento humano: em primeiro lugar, os estados intencionais consistem num conteúdo em certo tipo mental. Em segundo lugar determinam as suas condições de satisfação, isto é, serão ou não satisfeitas, dependendo do fato de se o mundo se harmoniza com o conteúdo do estado. E, em terceiro lugar, por vezes eles fazem as coisas acontecer, mediante a causação intencional para produzir uma harmonia, isto é, para produzir o estado de coisas que representam, as suas próprias condições de satisfação.

A primeira característica sugerida por Searle acerca do conteúdo mental intencional foi alcançada e poderia ser resumida da seguinte forma: "queremos alimentar os macacos com bananas", de nossa parte, e da deles "adoramos bananas e queremos chegar o quanto antes na distribuição do referido alimento".

A segunda característica certamente também foi alcançada, já que nossos estados mentais intencionais não só encontraram condições de satisfação, como também se harmonizaram plenamente com o mundo, para usar os termos desse autor. E o mesmo pode ser dito igualmente da terceira 
característica proposta, já que os estados mentais intencionais dos macaquinhos e os nossos fizeram as coisas acontecerem e se harmonizaram não só entre si, mas também com o mundo.

Notemos também que a consciência e a intencionalidade (no nosso caso e no caso dos macacos) são recíprocas, e que o que varia de fato apenas são os graus de inteligência, consciência e intencionalidade que existem em nós. Como nos informa Desmond Morris (2004, p. 120),

é preciso notar que, apesar de termos adquirido um brilho verbal muito desenvolvido, continuamos a utilizar os mesmos sons básicos instintivos emitidos pelos outros primatas - grunhidos, gemidos e guinchos. As nossas expressões sonoras inatas mantêm-se, conservando mesmo papéis importantes. Não só providenciam as bases vocais com que construímos o nosso arranha-céu verbal, mas continuam a manter direitos próprios, como dispositivos de comunicação típicos da espécie. Ao contrário do que sucede com as expressões verbais, os sons básicos surgem sem treino preliminar e têm o mesmo significado, seja em que cultura for. O grito, a lamúria, a gargalhada, o guincho, o gemido e o chorar rítmico transmitem as mesmas mensagens, seja a quem for e seja onde for. Tal como os sons emitidos pelos outros animais, eles se relacionam com os estados emocionais básicos e dão-nos a impressão imediata das motivações de quem os emitiu. Nós retivemos igualmente as nossas expressões instintivas, o sorriso, 0 riso, o franzir de sobrancelhas, o olhar fixo, a cara de pânico e a face zangada. Essas expressões também são comuns a todas as sociedades, apesar da aquisição cultural de muitos gestos e maneirismos.

Além disso, para o horror dos antropocêntricos e logocêntricos, e atordoamento dos linguistas e mecanicistas fisicalistas, há flagrantemente nessa relação por nós relatada efetiva comunicação, ainda que cada um se expresse através de vocalizações também intencionais diferentes -à sua maneira e na sua linguagem-, e é possível dizer que ambos conseguimos alcançar nossos objetivos intencionais.

Ou seja, eu experimentei o prazer de alimentar esses delicados e astutos seres que habitam as matas, e eles, por sua vez, emitindo sons e me olhando nos olhos, como quem deseja entender a minha intenção subjetiva, vinham apanhar com as pequeninas mãos em minhas próprias mãos as fatias de banana que Ihes eram gentilmente ofertadas. Por vezes apoiando suas mãos nas minhas. Qual não foi o nosso regozijo ao vê-los comer bem de pertinho, ao perceber como educam carinhosamente os seus filhotes, levando-os nas costas para todos os lados, e como trafegam com desenvoltura entre os ramos e galhos -quase que como pássaros-, lançando-se pelos ares, e o quão todo aquele espetáculo natural da biologia viva confirmava as ideias de intencionalidade que aqui nesse texto são averiguadas, ver figuras 1,2 e 3 . 

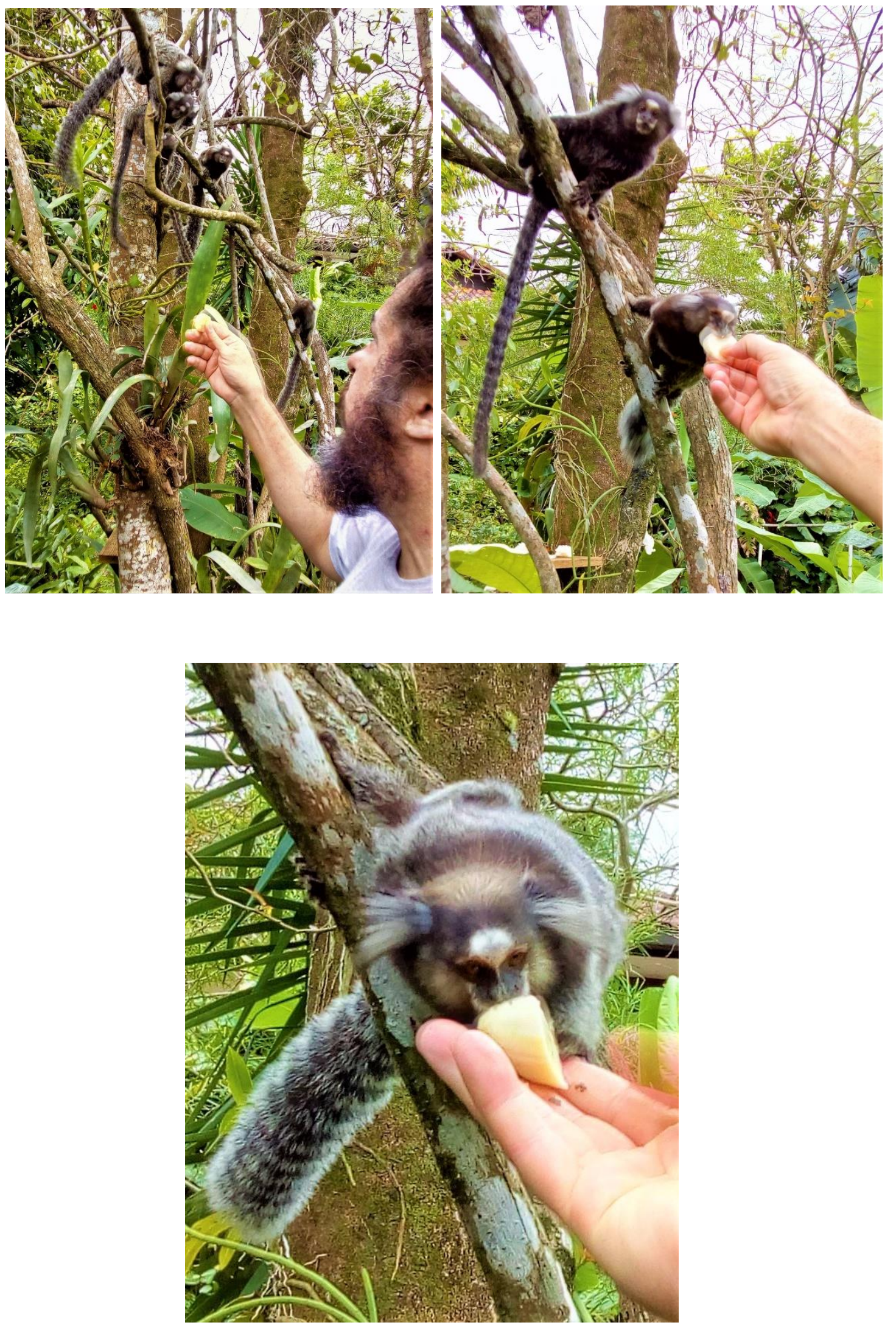

Figuras 1, 2 y 3. Macaquinhos silvestres da Mata Atlântica brasileira (Saguis; Saguido-nordeste; Callithrix jacchus) comendo banana na mão do autor. Itanhangá, Rio de Janeiro, inverno de 2018. Fotos: Christina Garcia. 
Diante de tudo isso, como negar que esses seres sejam inteligentes, conscientes e intencionais? A mãe miquinho que decide ceder seu naco de fruta madura ao bebê mico, o faz intencionalmente, pois 'sabe' que, assim como ela, ele sente fome, e ela também sabe que precisa protegê-lo. Ela não só sabe que ele sente fome, como também age sem dúvida intencionalmente de acordo com esse saber consciente, e esse saber, em última instância, significa ser capaz também de criar em sua própria mente subjetiva um modelo da mente subjetiva do outro (seu filhote, parceiro ou concorrente), de maneira a poder compreender suas necessidades e agir intencionalmente de acordo com isso. É claro que aqui não estamos defendendo que esses animais criam modelos da mente dos outros com a mesma complexidade com que fazemos isso, mas é indubitável que eles precisam saber -ainda que instintivamente- o que os outros estão pensando e sentindo, para aí então agir inteligentemente de acordo com isso.

Notemos que esse aporte reflexivo simples da biologia naturaliza o conhecimento, tornando-o mais acessível, e desembaraçando-o de quaisquer confusões teóricas e/ou conceituais. O metafísico não pode se insubordinar à física. As conjecturas não podem atropelar os fatos. Deslindar e tentar compreender o funcionamento da mente consciente e intencional, seja humana, seja animal, não pode consistir em ignorar o fato manifesto de sua ontologia própria, nem muito menos ainda na imposição de sistemas e regras arbitrárias. Num só termo, nossas teorias devem se adaptar à realidade, e não o contrário. Isso é o que manda o bom senso. John Searle (2010, pp. 139-140) nos sugere:

Consideremos o caso de um animal, um leão, digamos, que se move de modo aparentemente irregular em meio ao mato alto. O comportamento do leão será explicado se dissermos que ele espreita um antílope, que é a sua caça. O comportamento de espreitar é causado por um conjunto de estados intencionais: ele está faminto, ele quer devorar o antílope, ele tem a intenção de seguir o antílope com o objetivo de pegá-lo, matá-lo e devorá-lo. Seus estados intencionais representam estados possíveis das coisas no futuro e serão satisfeitos somente se esses estados vierem a verificar-se (direção de adequação mundo-mente); seu comportamento é uma tentativa de produzir esses estados (direção de causação mente-mundo).

Mas, mesmo que peguemos exemplos de animais menos, muito menos complexos que os que utilizamos como exemplo até aqui, ainda assim, poderemos encontrar níveis e graus de inteligência e intencionalidade. Gregory Bateson (1986, p. 54) nos traz um exemplo impressionante desse tipo de ocorrência intencional: "O carrapato sobe numa árvore e fica esperando num galho externo. Se sente o cheiro de suor, ele se atira, caindo talvez sobre um mamífero. Entretanto, se não sente cheiro de suor após algumas semanas, ele desce e procura outra árvore para subir". Enfim, quem "fica esperando", quem 
"sente o cheiro", quem "se atira", é sem dúvida o sujeito intencional, já que não há outra maneira.

Peter Godfrey-Smith (2019, p. 217) acrescenta que "a relação de mão dupla entre sentir e agir é característica de todos os organismos conhecidos, inclusive na vida unicelular". Winfried Nöth (2019, pp. 1-2), por seu turno, traz-nos a perspectiva de Michel de Montaigne, que mesmo em sua época já sabia instintivamente a respeito da subjetividade e da consciência dos animais:

\begin{abstract}
Montaigne 'é fundamentalmente um monista, ou seja, todas as faculdades psíquicas existentes nos animais são as mesmas que existem no homem. Para Montaigne, os animais julgam, comparam, raciocinam e agem da mesma forma que o homem; o mesmo e ainda melhor'. Essas ideias certamente posicionam Montaigne como um precursor filosófico da virada filosófica para os animais não humanos.
\end{abstract}

A percepção de que os animais são seres vivos como nós e não máquinas, como queria Descartes ou ainda quer Dennett, é um dado empírico observável e totalmente comprovável. Quaisquer tentativas de excluí-los dessa qualificação -segundo o nosso rude entendimento- seria uma mera arbitrariedade impositiva, sem nenhum valor científico ou acadêmico. Além disso, Winfried Nöth (2019, p. 10), evocando um outro filósofo que também nos inspira e que parece avalizar nossas asserções, sustenta que

para Peirce, a continuidade entre seres humanos e não humanos não é uma questão de continuidade entre seres com e sem mentes, mas um entre organismos de poderes mentais menos complexos e mais complexos. Os animais têm mentes, 'por mais estranhas que sejam, como as medusas, e até mesmo o próprio organismo microscópico do monge, cada um tem algo como uma mente com as duas potências mentais fundamentais' do Sentimento e do Esforço (CSP Papers, ms 659, G2-G3).

Nöth (2019, p. 12) acrescenta:

Em suma, embora o sentimento seja acessível apenas àquele que o experimenta, podemos e devemos inferir, por analogia, que outros, animais e seres humanos, têm sentimentos exatamente como nós. Precisamos reconhecer que nossas suposições sobre os modos de experiência e pensamentos dos outros requerem o mesmo tipo de inferência. 


\section{Intencionalidade biológica}

E se engana quem crê que comportamento inteligente e intencional se restringe a animais complexos que possuem cérebro. Hoje, diante de novas pesquisas, sabemos que plantas também tem comportamentos intencionais e inteligentes, e que isso se manifesta de diversas formas. Talvez um dos exemplos mais impressionantes desse tipo de intencionalidade presente em vegetais, seja o que nos oferece Peter Wohlleben (2017, pp. 13-14):

Há cerca de 40 anos cientistas notaram algo interessante na savana da África. As girafas comem a folhagem da Acacia tortilis, uma espécie de acácia que não gosta nem um pouco disso. Para se livrar dos herbívoros, poucos minutos depois de as girafas aparecerem as acácias bombeiam toxinas para as folhas. As girafas sabem disso e partem para as árvores próximas. Mas não tão próximas: primeiro elas pulam vários exemplares e só voltam a comer depois de uns 100 metros. 0 motivo é surpreendente: as acácias atacadas exalam um gás de alerta (no caso, etileno) que sinaliza às outras ao redor que surgiu um perigo. Com isso, liberam toxinas. As girafas conhecem a tática e por isso avançam savana a dentro até encontrarem árvores desativadas. Ou então trabalham contra o vento, já que é ele que carrega a mensagem aromática, buscando acácias que ainda não detectaram sua presença.

Notemos que aqui, nesse único exemplo, é possível identificar manifestações de intencionalidade diversas, e em níveis igualmente diferentes: tanto as árvores como as girafas se comportam de maneira inegavelmente inteligente e intencional, e, além disso, as acácias também exibem comportamentos típicos de inteligências coletivas, já que trabalham em grupo. Ou seja, são várias árvores trabalhando em conjunto e em cooperação para uma única finalidade comum, a saber, defenderem-se das famintas girafas. Ademais, como lemos em Peter Wohlleben (2017, p. 11), as razões -no caso específico das acácias, mas também das florestas- são obviamente sistêmicas:

Uma única árvore não forma uma floresta, não produz um microclima equilibrado; fica exposta, desprotegida contra o vento e as intempéries. Por outro lado, muitas árvores juntas criam um ecossistema que atenua o excesso de calor e de frio, armazena um grande volume de água e aumenta a umidade atmosférica - ambiente no qual as árvores conseguem viver protegidas e durar bastante tempo. [...] Cada árvore é valiosa para a comunidade [de árvores] e deve ser mantida viva o máximo possível. Mesmo os espécimes doentes recebem ajuda e nutrientes até ficarem curados. E uma árvore que no passado auxiliou outra pode no futuro precisar de uma mãozinha. Quando as enormes faias se comportam dessa forma, me fazem lembrar de uma manada de elefantes. A manada também cuida de seus membros, ajuda os indivíduos doentes e fracos e reluta até em deixar os mortos para trás.

Por outro lado, no que se refere à IA (Inteligência Artificial) e os computadores que 'rodam' seus sofisticados programas -que junto com a 
biologia e a bioevolução compõem justamente o núcleo de nosso objeto de estudo desta feita-, torna-se importante frisar que o problema da intencionalidade está intimamente ligado ao problema da consciência, que por sua vez está também ligado à questão da subjetividade sensível de um agente inteligente, que certamente se liga ao problema da emoção, cujos processos intrínsecos vinculam-se inquebrantavelmente a manifestações de nível superior de cérebros biológicos vivos, que são parte de organismos complexos formados por células e tecidos, e assim por diante. Daí a dificuldade em tentar reproduzir a intencionalidade em sistemas artificiais. Além disso, como nos informa John Searle (2010, p. 199),

no computador comercial, como já vimos, os símbolos, as frases, a representação, a informação e o cômputo são todos relativos ao observador. Do ponto de vista intrínseco, o computador é somente um circuito eletrônico complicado. Para que o computador satisfaça a restrição da realidade causal, temos de recorrer a programadores, planejadores e usuários que atribuem uma interpretação ao input, aos processos intermediários e ao output. Em relação ao computador comercial, somos os homúnculos $\left[{ }^{1}\right]$ que dão sentido a toda a operação.

Searle (2010, p. 200) continua: "Segundo a ideia do modelo de processamento de informação, a informação no sistema é transportada pelos cômputos que se operam sobre a sintaxe. A semântica vai de carona. Mas [...] é a sintaxe que vai de carona. A intencionalidade intrínseca do agente faz tudo". E um ser vivo consciente e intencional, que precisa tomar decisões determinantes em frações de segundos por pressões do ambiente, não poderia fazer primeiro cálculos aritméticos para então poder agir performativamente no mundo -seja lutando, seja fugindo-, sob pena de ser devorado ou morto antes mesmo de ter formulado logicamente o cálculo a ser efetuado para o pretenso movimento. Isso simplesmente não faz sentido em termos bioevolutivos, e nem muito menos ainda em termos práticos. Mas, ainda assim, como nos informa Francisco Varela (2017, p. 31), "se pretendemos que os estados intencionais têm propriedades causais, temos de mostrar não apenas como estes estados são fisicamente possíveis, mas também em que medida podem determinar um comportamento".

Mas, como escreve Nick Bostrom (2018, p. 41), é interessante perceber que, assim como "o cientista da computação Donald Knuth observou, 'a IA tem tido sucesso até agora em fazer essencialmente tudo o que requer pensar, mas tem falhado em fazer a maior parte daquilo que as pessoas e os animais fazem sem pensar -isso, de alguma forma, é muito mais difícil'". Como sustenta John Searle (2010, pp. 202-203),

as pessoas são perfeitamente capazes de fazer inferências lógicas. Elas o fazem, segundo a explicação, seguindo regras das quais são totalmente inconscientes e 
que nem sequer poderiam formular sem ajuda profissional. Assim, por exemplo, as pessoas fazem inferências usando o modus ponens, embora não saibam formular esta regra e não disponham desse conceito. [...] As inferências não derivam sua validade do modus ponens. Ao contrário, o modus ponens deriva sua validade autônoma das inferências. [...] Quando subtraio o conteúdo semântico das proposições, aí sim a regra do modus ponens passa a desempenhar um papel.

Sim, pois temos internalizadamente uma perspectiva de mundo, uma noção histórica, uma conceituação e valoração do que seja bom, belo, gratificante, aprazível, louvável e assim por diante. Assim como temos, igualmente, a lógica completamente internalizada em nossas ações. Todavia, indagamos juntamente com Nick Bostrom (2018, p. 335):

Mas como implantar algum valor em um agente artificial de modo que ele venha a buscar esse valor como seu objetivo final? Em qualquer domínio mais complicado que um jogo da velha, existem muitos estados possíveis (e histórias possíveis) para que uma enumeração exaustiva seja factível. Assim, um sistema de motivações não pode ser especificado de forma tabular.

Mas não nos enganemos, pois existe muito esforço envolvido nesse projeto de instanciar uma intencionalidade de máquina em sistemas cibernéticoinformacionais de IA. Muitas são as abordagens em relação ao problema da intencionalidade, e muitas também são as formas possíveis de resolvê-lo. Nick Bostrom (2018, p. 335) sugere que o sistema ao invés de possuir uma mente completa, que já contenha representações e memórias do mundo, ele deve, "ao contrário, ser expresso de forma mais abstrata, como uma fórmula ou regra que permita ao agente decidir o que fazer em uma dada situação". Aqui reaparece a ideia que o pioneiro Alan Turing já previa de uma IA criança, dotada de um mínimo de regras e parâmetros, adquirindo-os progressiva e heuristicamente conforme explora e conhece o mundo ao seu redor.

Lembrando que, como escrevem Francisco Varela, Evan Thompson e Eleonor Rosch (1991, p. 267),

de um modo geral, a intencionalidade tem duas vertentes: em primeiro lugar, a intencionalidade inclui o modo como o sistema [vivo] interpreta a forma como o mundo é (especificado em termos do conteúdo semântico de estados intencionais); em segundo lugar, a intencionalidade inclui o modo como o mundo satisfaz ou não consegue satisfazer esta interpretação (especificada em termos de condições de satisfação e estados intencionais). Poderíamos então dizer que a intencionalidade da cognição como ação corporalizada consiste primeiramente no caráter direto da ação. 
Dito de um modo mais simples, a cognição -em última instância e no extremo- visa a ação inteligente e intencional no mundo ontofenomênico. Visa um performar mais efetivo e eficiente no ambiente.

\section{Intencionalidade cognitiva}

Avançando um pouco mais nessa visão sistêmica dos organismos vivos e seus meios circundantes, notemos juntamente com Varela, Thompson e Rosch (1991, p. 268), que

há dois domínios no âmbito dos quais podemos descrever qualquer sistema cognitivo: por um lado podemos debruçar-nos sobre a estrutura do sistema descrevendo-o como sendo composto por vários subsistemas, etc., e, por outro lado podemos debruçar-nos sobre as interações comportamentais do sistema, descrevendo-o como uma unidade capaz de várias formas de acoplamento.

De modo que, para concluir essa breve visão sistêmica dos organismos vivos -com a qual nos alinhamos completamente-, e conseguir também acentuar o âmbito da cognição como algo importante que acontece somente por meio do acoplamento estrutural dos indivíduos vivos no ambiente, vejamos essas definições de Francisco Varela, Evan Thompson e Eleonor Rosch (1991, p. 269):

Pergunta 1: O que é cognição? Resposta: Atuação: uma história de acoplamento estrutural que produz um mundo. Pergunta 2: Como funciona? Resposta: Através de uma rede constituída por níveis múltiplos de subredes sensoriomotoras interligadas. Pergunta 3: Como sei quando um sistema cognitivo está a funcionar adequadamente? Resposta: Quando se torna parte de um mundo existente continuadamente (como no caso dos jovens de todas as espécies) ou forma um novo (como acontece na história evolucionária).

Mas -é bom que se diga-, as nossas reflexões e também as de Varela, Thompson e Rosch, por mais razoáveis que pareçam, estão muito longe de expressar o consenso entre pesquisadores e teóricos destes campos, e muito menos ainda ser o modelo utilizado pelo poder hegemônico das ciências cognitivas atuais. E o mesmo vale para as neurociências e sistemas pretensamente inteligentes de IA, pois, como esses mesmos autores referenciam (1991, p. 269), "muito daquilo que aparece nestas respostas [que se encontram na citação acima] tem estado ausente da ciência cognitiva -não apenas do cognitivismo mas também do conexionismo atual mais avançado".

O que significa dizer, em termos bem gerais, que vigoram outras crenças, outros modelos e outros paradigmas. E essas crenças e paradigmas, que comparam máquinas a organismos vivos, tiveram origem -também- nos 
primeiros tempos da cibernética. Vejamos, por exemplo, a posição de McCulloch, nessa citação de Jean-Pierre Dupuy (1995, p. 53), que faz referência à edição de 1955 das Conferências Macy: "Quanto mais apreendemos sobre os organismos, mais somos levados a concluir que eles não são simplesmente análogos às máquinas, mas são máquinas [grifo do autor]". Longe de compreender como as coisas realmente acontecem no âmbito biológico, "tratava-se antes", acrescenta Dupuy (1995, p. 98), "de alcançar, no domínio das ciências da mente, o mesmo grau de objetividade que na física".

Nesse sentido, fazemos nossas as palavras de Varela, Thompson e Rosch (1991, p. 269), quando escrevem o seguinte: "defendemos que sem as noçõeschave da abordagem da atuação, a ciência cognitiva será incapaz tanto de explicar a cognição viva como de construir artefatos cognitivos verdadeiramente inteligentes". Ainda em referência a essa comparação tosca entre cérebros e computadores, Karl Lashley apud Howard Gardner (1995, p. 279) sustenta:

O cérebro tem sido comparado a um computador digital porque o neurônio, como um comutador ou válvula, ou completa ou não completa um circuito. Mas neste ponto a semelhança termina. O comutador do computador digital tem um efeito constante, e seu efeito é grande em proporção ao output total da máquina. O efeito produzido pelo neurônio varia com a sua recuperação da fase refratária e com seu estado metabólico. O número de neurônios envolvidos em qualquer ação chega a milhões, de forma que a influência de qualquer um deles é desprezível... Qualquer célula do sistema pode ser dispensada.

Já em um sistema cibernético-informacional, como um computador comercial, por exemplo, um dígito errado ou perdido pode comprometer toda a computação que se está a efetuar. Num sistema binário e determinístico como esse, regido pela lógica matemática, basta apenas um algarismo perdido ou imprecisamente grafado, para que toda a operação computacional esteja absolutamente arruinada.

Além disso, como já vimos no início desse artigo, o problema da intencionalidade evoca -em relação às IA- questões da seguinte natureza: só haverá intencionalidade se houver um agente, um ente, enfim, um ser vivo com subjetividade própria, que, nesse sentido, nada mais é do que uma visão própria em primeira pessoa do mundo em que ele mesmo está inserido. Para haver intenção tem de haver necessariamente um eu. E é justamente esse sujeito singular que irá expressar e ter toda e quaisquer intenções. É por isso que John Searle (2006, p. 138) escreve que

os estados e processos mentais conscientes têm uma característica especial, não encontrada em outros fenômenos naturais, a saber, a subjetividade. É esta característica da consciência que torna seu estudo tão teimosamente desafiador 
aos métodos convencionais da pesquisa biológica e psicológica, e mais confuso para a análise filosófica.

\section{Intencionalidade bacteriana}

Antes de concluir, é bom lembrar que -não em todos, mas em muitos sentidosaté bactérias podem ser consideradas seres minimamente intencionais e cognitivos, enquadrando-se nas três respostas apresentadas como condicionais para a cognição por Varela, Thompson e Rosch (1991, p. 269), mencionada anteriormente. Vejamos então as indagações e suas respostas, acrescidas de nossos breves comentários: (1) "O que é cognição? Atuação: uma história de acoplamento estrutural que produz um mundo", e nesse ponto é inegável que elas estão acopladas estruturalmente e produzem mundo -é claro-, um mundo e acoplamento de bactéria; (2) "Como funciona?" "Através de uma rede constituída por níveis múltiplos de subredes sensoriomotoras interligadas", ora elas (bactérias) também se constituem redes interligadas, que fazem conexão com subredes internas que se comunicam, já que são informadas do que se passa em seu meio externo e agem de acordo; e (3) "Como sei quando um sistema cognitivo está a funcionar adequadamente? Quando se torna parte de um mundo existente continuadamente (como no caso dos jovens de todas as espécies) ou forma um novo (como acontece na história evolucionária)", o que elas definitivamente também fazem, já que bactérias nadam, se movimentam livremente sem controle externo e ainda escolhem suas direções nesse seu movimentar.

Além disso, elas também são as responsáveis pela produção da nova geração de bactérias. Vejamos o que nos oferta Peter Godfrey-Smith (2019, p. 23) acerca dessas nossas formidáveis e ancestrais companheiras terráqueas chamadas bactérias:

[A bactéria] E. coli [...] vive em grande número dentro e em volta de nós. A E. coli tem o sentido do paladar ou do olfato; é capaz de detectar substâncias químicas bem-vindas e indesejadas e de reagir a isso -indo em direção a concentrações de algumas e afastando-se das outras. O exterior de cada célula $E$. coli tem uma rede de sensores - coleções de moléculas que se conectam à membrana exterior da célula. Este é o input do sistema. O output é composto pelos flagella, os longos filamentos que a célula usa para nadar. Uma bactéria $E$. coli faz dois movimentos principais: pode correr ou rodopiar. Quando corre, movimenta-se em linha reta; quando rodopia, como seria de esperar, fica mudando de direção aleatoriamente. A célula alterna continuamente essas duas atividades, mas se detectar uma concentração crescente de alimento, reduz os rodopios.

Enfim, a E. coli, em sua pretensa simplicidade, não deixa de exprimir algum nível de percepção e intencionalidade cognitiva em seu rudimentar 
performar, e mais, ela também exibe comportamento inteligente, seja indo em direção à comida, seja fugindo de ameaças. O polvo, da família dos moluscos, também é capaz de expressar flagrante intencionalidade. Acompanhemos esse outro exemplo ofertado também por Godfrey-Smith (2019, p. 78):

Quando você encontra um polvo em um ambiente natural, se aproxima dele e para à sua frente, pelo menos em algumas espécies o polvo estenderá um braço para inspecionar você. Frequentemente, um segundo braço virá em seguida, mas sempre é um único que vem primeiro, enquanto o animal observa. Isso sugere um tipo de intencionalidade, uma ação guiada pelo cérebro.

Ademais, conclusivamente, o computador ou robô que expressar algum tipo de comportamento inteligente não terá ipso facto uma intencionalidade subjetiva particular, ele apenas estará a executar rigidamente um programa ou conjunto de parâmetros que, por sua natureza altamente determinística de protocolos, rotinas, sub-rotinas e comandos, determinará a priori o que ele irá fazer em cada situação, de maneira que seja compreendido como inteligente por nós, que os concebemos, construímos, programamos e usamos. Há, além disso -observemos-, uma enorme diferença entre ser vivo, consciente e intencional -por um lado-, e ser -por outro- uma máquina algorítmica que segue rígidas regras computacionais em forma de linguagem binária.

A inteligência não pode ser medida com base no comportamento externo do robô, androide ou computador que construirmos, e sim por uma análise lógica de seu meio interno, sua constituição, sua história e seu hipotético acoplamento estrutural com a realidade. Somente um sistema tão complexo como o cérebro biológico vivo poderá exibir comportamentos que possam ser classificados como genuinamente inteligentes. E, em relação a isso, estamos ainda muito longe de consegui-lo. Para saber se será possível ou não uma intencionalidade cibernético-informacional, faz-se necessário aguardar.

\section{Intencionalidade artificial e o problema dos qualia}

Antes de mais nada, é preciso dizer que computadores, androides e robôs são artefatos tecnológicos, e que artefatos tecnológicos de forma alguma possuem intencionalidade própria. Isto parece ser um ponto acordadamente pacífico. Mas, uma hipotética intencionalidade artificial talvez -ao contrário da subjetividade e do agente- possa não ser um problema tão grande assim em termos de realização e programação de software, por exemplo -é claro, desde o ponto de vista imaginário do robô, e do nosso, que o antropomorfizamos-, pois ela poderia ser simulada com menos dificuldades por meio de rotinas e protocolos relativamente simples, já que, na prática, a finalidade útil da máquina quase se funde com o que seria a sua intencionalidade hipotética, 
tendo em vista que externamente a intencionalidade dele (robô) se expressaria como cumprimento da função e execução do que lhe foi programado.

O que queremos dizer é que aos nossos olhos humanos, a intencionalidade é extremamente complexa, cheia de nuances e motivações múltiplas, absolutamente repleta de ponderações e raciocínios abstratos complexos -ainda que, como alguns autores apontem muito bem, muito do que fazemos seja inconsciente-, o que na prática nos permite interagir e performar num mundo em constante movimento e transformação, ações e funções que necessariamente requerem uma mente consciente para poderem se organizar e manifestar em pura complexidade, transformando-a em intencionalidade, ou seja, em comportamento inteligente.

De modo que seria crível determinar para o sistema que sua intencionalidade passe, necessariamente, pela execução à risca de seu programa de finalidade objetiva. Todavia, como nos referimos a máquinas e sistemas de IA, onde se pretende justamente que a máquina seja um agente artificial relativamente autônomo, inspirada em nossa própria autonomia, e que ainda exprima um comportamento minimamente consciente, a coisa toda muda de figura. Notemos que a intencionalidade -como vimos- depende de um agente consciente, pois é justamente esse agente que possuirá intencionalidade.

Mas, ainda que possa parecer absurdo, extrapolemos o momento atual, e imaginemos um futuro relativamente próximo, em que máquinas com diversos níveis e graus diferentes de consciência e intencionalidade artificiais estarão interagindo conosco socialmente, e pensemos no que seria importante. Intencionalidade consciente -como sabemos- tem a ver com livre arbítrio, e livre-arbítrio diz respeito a valores e significados. A pergunta premente num contexto assim seria: o que regerá essas relações? Que tipo de código ou lei normatizará tal interação social? As Três Leis da Robótica ${ }^{2}$ não serão absolutamente capazes de nos proteger, em caso de falhas nos sistemas, pane, mau-funcionamento ou colapso. Mas, imaginando que esses sistemas estejam em operação e funcionando bem, qual seria a forma de articular uma percepção artificial que pudesse gerar uma forma de intencionalidade neles? Como seria a sua experiência subjetiva do mundo? Raúl Arrabales, Agapito Ledezma e Araceli Sanchis (2010) argumentam que,

embora tendemos a acreditar que percebemos a realidade, o fato é que os qualias gerados em nossos cérebros estão longe de ser uma representação verdadeira do mundo real. No entanto, geralmente a nossa experiência consciente do mundo revela-se altamente confiável em termos de tarefas diárias.

A ideia basal parece ser associar ações e comportamentos que assumimos -em tese- inconscientemente, como se fizéssemos numa espécie 
de modo automático -utilizando o tipo de metáfora maquínica que nós mesmos criticamos-, de modo que fosse possível replicar artificialmente. Raúl Arrabales, Agapito Ledezma e Araceli Sanchis (2010) acrescentam que,

em suma, o mundo é interpretado pelo sujeito de tal forma que é vantajoso para seus objetivos. A definição intuitiva anterior da percepção consciente não parece ser suficiente para construir um modelo detalhado de uma máquina consciente que inclua aspectos fenomenais.

A realidade da consciência, de acordo com isso, seria uma interpretação, e interpretação é interpretação de percepções, significados, sentidos, qualidades. $\mathrm{E}$, em se tratando de fenomenologia, a própria problematização nos remete novamente à questão dos qualia, assunto tratado em artigo pregresso (Inteligências artificiais e o problema da consciência, Alexandre Quaresma 2018). Conclusivamente, em uníssono com Massimo Negrotti (2012, p. 406), "podemos afirmar que tudo o que acontece em nosso cérebro é [metaforicamente ${ }^{3}$ ] 'silencioso' e possivelmente muito bem escondido nas microestruturas e redes de interações dentro do cérebro".

\section{Referências bibliográficas}

Arrabales, Raúl; Ledezma, Agapito e Sanchis, Araceli. (2010). On the practical nature of artificial qualia. Proceeding of: 2010 Annual Convention of the Society for the Study of Artificial Intelligence and Simulation of Behaviour (AISB 2010), Leicester, UK, 29 March - 1 April.

Austin, John. (2004). Sentido e percepção. São Paulo: Martins Fontes.

Bateson, Gregory. (1986). Mente e natureza: A unidade necessária. Rio de Janeiro: Francisco Alves.

Bostrom, Nick. (2018). Superinteligência - Caminhos, perigos e estratégias para um novo mundo. Rio de Janeiro: DarkSide Books.

Depuy, Jean-Pierre. (1995). Nas origens das ciências cognitivas. São Paulo: Editora UNESP.

Gardner, Howard. (1995). A nova ciência da mente. São Paulo: EDUSP.

Godfrey-Smith, Peter. (2019). Outras mentes: O polvo e a origem da consciência. São Paulo: Todavia.

Kaku, Michio. (1997). Visões de futuro - Como a ciência revolucionará a o século XXI. Rio de Janeiro: Rocco.

Morris, Desmond. (1967). O macaco nu - Um estudo do animal humano. Rio de Janeiro: Record. 
Negrotti, Massimo. (2012). From the Natural Brain to the Artificial Mind. In L. Swan (ed.) Origins of Mind, Biosemiotics 8, DOI 10.1007/978-94-007-5419-5_21, Springer Science+Business Media Dordrecht.

Nicolelis, Miguel. (2011). Muito além do nosso eu. São Paulo: Companhia das Letras. Nöth, Winfried. Manual de semiótica. São Paulo: EDUSP, (no prelo).

Nöth, Winfried. (2019). Peirce on the continuity between human and nonhuman minds. In Texts, Animals, Environments: Zoopoetics and Ecopoetics, Frederike Middelhoff, Sebastian Schönbeck, Roland Borgards \& Catrin Gersdorf (eds.), pág. 121-134. Freiburg, Br: Rombach.

Quaresma, Alexandre. (2019). Inteligências artificiais e o problema da consciência. In PAAKAT, Revista de Tecnología y Sociedad, núm. 16 (9). Guadalajara, México.

Searle, John. (1998). O mistério da consciência. São Paulo: Editora Paz e Guerra.

Searle, John. (2002). Intencionalidade. São Paulo: Martins Fontes.

Searle, John. (2006). A redescoberta da mente. São Paulo: Martins Fontes.

Searle, John. (2010). Consciência e linguagem. São Paulo: WMF/Martins Fontes.

Searle, John. (2017). Mente, cérebro e ciência. Lisboa: Edições 70.

Varela, Francisco. (2017). Conhecer - As ciências cognitivas, tendências e perspectivas. Lisboa: Instituto Piaget.

Varela, Francisco; Thompson, Evan e Rosch, Eleonor. (1991). A mente corpórea Ciência cognitiva e experiência humana. Lisboa: Instituto Piaget.

Wheeler, Michael. (2005). Reconstructing the Cognitive World: The Next Step. A Bradford Book, The MIT Press Cambridge, Massachusetts, London, England.

Wohlleben, Peter. (2017). A vida secreta das árvores - O que elas sentem e como se comunicam. Rio de Janeiro: Sextante.

Este artículo es de acceso abierto. Los usuarios pueden leer, descargar, distribuir, imprimir y enlazar al texto completo, siempre y cuando sea sin fines de lucro y se cite la fuente.

\section{CÓMO CITAR ESTE ARTÍCULO:}

Quaresma, A. (2020). Inteligências artificiais e o problema da intencionalidade. Paakat: Revista de Tecnología y Sociedad, 10(18). http://dx.doi.org/10.32870/Pk.a10n18.403

\footnotetext{
* É ensaísta e filósofo brasileiro, pesquisador de tecnologias e consequências socioambientais, com especial interesse na crítica da tecnologia. Autor dos livros Artificial Intelligences - Essays on Inorganic and Non-biological Systems (org.), (2019); Humano-Pós-Humano - Bioética, conflitos e dilemas da Pós-modernidade (2014); Engenharia genética e suas implicações (org.), (2014); e Nanotecnologias: Zênite ou Nadir? (2011). Atualmente é Mestrando em Tecnologias da
} 
Inteligência e Design Digital pela PUC/SP. E-mail: a-quaresma@hotmail.com. Lattes: http://lattes.cnpq.br/6089915050124806

${ }^{1} \mathrm{~A}$ ideia é que haveria um homenzinho dentro de nossas cabeças, de nossos cérebros, que leria e interpretaria esses símbolos.

2 São essas as Três Leis da Robótica concebidas pelo escritor de ficção científica Isaac Asimov: 1) Um robô não pode prejudicar um ser humano ou, por inação, permitir que um ser humano sofra algum dano. 2) Um robô deve obedecer às ordens que lhe são dadas por seres humanos, exceto quando tais ordens conflitarem com a Primeira Lei. 3) Um robô deve proteger sua própria existência, contanto que tal proteção não entre em conflito com a Primeira ou com a Segunda Lei (Asimov apud Kaku 1997, p. 164).

3 Metaforicamente porque já existem experimentos com implantes neurais que permitem a amplificação do som da própria atividade neuronal, o que vale dizer, os ruídos dos disparos dos neurônios, da atividade cerebral e das tempestades neuronais, como consta em Miguel Nicolelis (2011). 